Article

\title{
Intra-Plant Variability for Heat Tolerance Related Attributes in Upland Cotton
}

\author{
Aneeq ur Rehman ${ }^{1}$, Iqrar Ahmad Rana ${ }^{2,+}$, Sajid Majeed ${ }^{1}$, Muhammad Tanees Chaudhary ${ }^{1}$, Mujahid Zulfiqar ${ }^{1}$, \\ Seung-Hwan Yang ${ }^{3, *(\mathbb{D})}$, Gyuhwa Chung ${ }^{3}(\mathbb{D})$, Yinhua Jia ${ }^{4}$, Xiongming Du ${ }^{4}\left(\mathbb{D}\right.$, Lori Hinze ${ }^{5}$ \\ and Muhammad Tehseen Azhar 6,7,*(D)
}

\section{check for} updates

Citation: Rehman, A.u.; Rana, I.A.; Majeed, S.; Chaudhary, M.T.; Zulfiqar, M.; Yang, S.-H.; Chung, G.; Jia, Y.; Du, X.; Hinze, L.; et al. Intra-Plant Variability for Heat Tolerance Related Attributes in Upland Cotton. Agronomy 2021, 11, 2375. https:// doi.org/10.3390/agronomy11122375

Academic Editors:Channapatna S. Prakash, Ali Raza, Xiling Zou, Daojie Wang and Sheng Chen

Received: 25 September 2021 Accepted: 19 November 2021 Published: 23 November 2021

Publisher's Note: MDPI stays neutral with regard to jurisdictional claims in published maps and institutional affiliations.

Copyright: (c) 2021 by the authors Licensee MDPI, Basel, Switzerland. This article is an open access article distributed under the terms and conditions of the Creative Commons Attribution (CC BY) license (https:/ / creativecommons.org/licenses/by/ $4.0 /)$.
1 Department of Plant Breeding and Genetics, University of Agriculture, Faisalabad 38040, Pakistan; aneequrrehman57@gmail.com (A.u.R.); sajidmajeedpbg@gmail.com (S.M.); tanees_ch227@yahoo.com (M.T.C.); mujahidzulifiqar786@gmail.com (M.Z.)

2 Centre of Agricultural Biochemistry and Biotechnology, University of Agriculture, Faisalabad 38040, Pakistan iqrar_rana@uaf.edu.pk

3 Department of Biotechnology, Chonnam National University, Gwangju 59626, Korea; chung@chonnam.ac.kr

4 State Key Laboratory of Cotton Biology, Institute of Cotton Research of the Chinese Academy of Agricultural Sciences, Anyang 455000,China; jiayinhua_0@sina.com (Y.J.); duxiongming@caas.cn (X.D.)

5 Southern Plains Agricultural Research Center, USDA, Agricultural Research Service, College Station, TX 77845, USA; lori.hinze@usda.gov

6 Institute of Molecular Biology and Biotechnology, Bahauddin Zakariya University, Multan 60800, Pakistan

7 School of Agriculture Sciences, Zhengzhou University, Zhengzhou 450052, China

* Correspondence: ymichigan@jnu.ac.kr (S.-H.Y.); tehseenazhar@gmail.com (M.T.A.)

† Equal Co-First Authorship.

Abstract: Abiotic stress, particularly heat stress, affects various parts of the cotton plant and ultimately impacts the seed cotton yield. Different portions of a single cotton plant of a cultivar exhibit variable responses to stress during reproductive and vegetative phases. To test this hypothesis, physiological and morphological traits related to heat stress were observed for two flowering positions in 13 genotypes of upland cotton. These genotypes were sown in field conditions in triplicate following a randomized complete block design. Data were collected for pollen germination, pollen viability, cell membrane thermostability, chlorophyll content, boll weight, and boll retention for both the top and bottom branches of each genotype. The collected data were analyzed for the identification of variability within and between genotypes for these two flowering positions. Tukey's test was applied to estimate the significance of differences between genotypes and positions within each genotype. Results showed that the two positions within the same plant statistically varied from each other. The bottom branches of the genotypes performed significantly better for all traits measured except boll weight. The genotype AA-933 performed best for pollen germination and boll retention, while CYTO-608 exhibited maximum pollen viability in both the bottom and top flower positions compared with other genotypes. Overall, MNH-1016 and CIM-602 showed better cell membrane thermostability and chlorophyll content, respectively. This intra-plant variability can be further exploited in breeding programs to enhance the stress tolerance capabilities of the resulting varieties.

Keywords: genetic variability; Gossypium hirsutum; intra-plant variation; heat tolerance

\section{Introduction}

Cotton is a Kharif season crop grown mainly for feed, fiber, and oil in the Punjab and Sindh regions of Pakistan. These are considered hot regions since the temperature reaches $47^{\circ} \mathrm{C}$ during the growing season. Environmental stresses such as heat, and drought affect cotton plants by impeding normal physiological processes which lead to morphological abnormalities and yield reduction [1]. Plants mostly invest their defense in the most valuable sections, such as reproductive parts under various stress conditions. Cotton production is vulnerable to abiotic stresses, particularly during the growth stages of 
blooming and boll formation, which have become more frequent as our climate changes [2] Any stress during this stage abruptly reduces the yield. Numerous efforts have been made to understand the physiological, molecular, and genetic pathways of the cotton plant related to sustaining yield under stress conditions [3,4].

The reproductive efficiency of the cotton crop is negatively impacted by temperatures above $32{ }^{\circ} \mathrm{C}$ in a variety of ways, including reduced metabolism as well as suppression of photosynthesis, pollination, fertilization, and crop growth rate [5]. Heat and drought stress causes male gametes to undergo metabolic and structural changes that result in meiotic abnormalities or premature spore abortion [6]. It also results in poor pollen germination and short pollen tube growth in cotton $[7,8]$. It was reported that pollen germination is better in flowers that have been pollinated under the canopy of the plant as compared to flowers that are directly exposed to sunlight and pollinated during high-temperature stress [9].

Yield reduction is also associated with certain changes in metabolic and biochemical pathways in plant cells, i.e., excessive accumulation of reactive oxygen species (ROS) such as $\mathrm{H}_{2} \mathrm{O}_{2}$, singlet oxygen, hydroxyl ions, etc., during stress conditions [10]. As a result of a dramatic accumulation of ROS during stress, programmed cell death has been observed in developing pollen grains [11]. Hence, ROS scavenging through the action of antioxidants in anthers has a role in maintaining pollen viability under abiotic stress [12]. Under high temperature or water deficit conditions, the role of the cell membrane in maintaining cell osmotic balance may be impeded due to leakage of electrolytes [13]. In cotton, temperatures over $35^{\circ} \mathrm{C}$ increased membrane leakage and reduced leaf size [14]. High canopy temperature adversely affects the chlorophyll content in leaf tissues and lowers the rate of photosynthesis and carbohydrate production [15]. Reduction in carbohydrate content is also associated with decreased lint yield [16]. Cotton plants will shed bolls when they are stressed, thus boll retention drops significantly under harsh environmental conditions $[17,18]$.

It was noticed that different portions of a single cotton plant of a cultivar exhibit variable responses to stress during reproductive and vegetative phases. Although every cell in a plant has the same genetic material, the different behavior might be due to epigenetic $[19,20]$ or other effects. Every cell expresses itself according to the stimulus received from the environment. Young leaves are more resistant to insect damage compared to old ones [21]. So, every part of the plant faces a different environment. As a result, these positions phenotypically behave differently. Cultivars also differ in canopy shape and intra-plant morphological features. Moreover, cultivars are grown in the same region exhibit variation among them. Environmental and genotypic effects both contribute to the phenotype. Therefore, the objective of this study was to identify inter- and intra-cultivar variability for physiological as well as morphological attributes associated with the yield of seed cotton under heat stress conditions.

\section{Materials and Methods}

\subsection{Genotypes and Experimental Design}

This experiment was performed in the field area of the Department of Plant Breeding and Genetics, the University of Agriculture, Faisalabad located at $31.4504^{\circ} \mathrm{N}, 73.1350^{\circ} \mathrm{E}$, Pakistan. Thirteen genotypes of cotton were collected from the germplasm units of the Central Cotton Research Institute (CCRI), Multan; Cotton Research Institute (CRI), Multan; Cotton Research Station (CRS), Faisalabad; and other institutes in Pakistan listed in Table 1. These genotypes have different genetic backgrounds, have genetic variability, and grow well in the ecological niche present in the field area for this experiment. Cotton genotypes were sown on 16 May 2019 in three replications under a randomized complete block design (RCBD). Plots were single rows, 10 feet $(3.1 \mathrm{~m})$ long with a plant-to-plant distance of 12 inches $(30 \mathrm{~cm})$. Distance between rows was 30 inches $(76 \mathrm{~cm})$. All agronomic practices, including thinning, irrigation, weeding, and plant protection measures were performed at the appropriate crop growth stage according to cotton production technology 
approved for the Punjab province by the Directorate of Agriculture to maintain a healthy plant population.

Table 1. List of 13 cotton genotypes of G. hirsutum L. evaluated for heat tolerance.

\begin{tabular}{|c|c|c|c|}
\hline $\mathrm{Sr} \#$ & Genotype Name & Origin & Prominent Characteristics \\
\hline 1 & CRS-2 & Advance strain & Spreading growth habit, creamy yellow pollens, heat tolerant. \\
\hline 2 & VH-377 & CRS Vehari & Medium leaf pubescence, creamy pollen color, Good fiber quality. \\
\hline 3 & FH-215 & CRS Faisalabad & $\begin{array}{l}\text { Resistant to CLCuV and pink bollworm, moderate pubescence on } \\
\text { leaves, semi-erect branches. }\end{array}$ \\
\hline 4 & CIM-343 & CCRI Multan & Heat and drought tolerant, high yielding Bt-variety [22] \\
\hline 5 & CIM-602 & CCRI Multan & Early maturity, high lint percentage, and heat tolerant Bt-variety [23] \\
\hline 6 & MNH-1016 & CRI Multan & $\begin{array}{l}\text { Semi erect branches, stem pigmentation, creamy pollen color, round } \\
\text { shape boll, tolerant to } C L C u V \text {, high yielding Bt variety }\end{array}$ \\
\hline 7 & MNH-1026 & CRI Multan & $\begin{array}{l}\text { Medium compact growth habit, semi-erect branches, creamy pollen, } \\
\text { oblong boll shape, CLCuV tolerant, white fiber color, high yielding } \\
\text { Bt variety }\end{array}$ \\
\hline 8 & NIBGE-2 & NIBGE Faisalabad & $\begin{array}{l}\text { Resistant to Multan and Burewala strain of } \mathrm{CLCuV} \text {, Drought resistant, } \\
\text { Spreading growth habit. [24] }\end{array}$ \\
\hline 9 & N-777 & NIAB Faisalabad & High-density planting cotton, tolerant to heat and CLCuV-B strain. [25] \\
\hline 10 & N-1048 & NIAB Faisalabad & Tolerant to CLCuV, Spreading growth habit. \\
\hline 11 & CYTO-124 & CCRI Multan & Highly CLCuV tolerant, Non-Bt interspecific variety [23] \\
\hline 12 & CYTO-608 & CCRI Multan & Non-Bt interspecific variety [23] \\
\hline 13 & AA-933 & Ali Akbar group, Multan & $\begin{array}{l}\text { Heat tolerant, good fiber quality, resistant to CLCuV, yellow pollen } \\
\text { color. Spreading growth habit. }\end{array}$ \\
\hline
\end{tabular}

CRS = Cotton Research Station, CCRI = Central Cotton Research Institute, CRI = Cotton Research Institute, NIBGE = National Institute for Biotechnology and Genetic Engineering, NIAB = Nuclear Institute for Agriculture and Biology.

\subsection{Data Collection}

Heat tolerance measurements were taken during the growing season when $50 \%$ of the crop was flowering. Each plant was divided into two equal parts by measuring plant height in such a way that the bottom portion was under the shade of the plant canopy while the upper portion was exposed to direct sunlight. Flowers in the top part of the plant were exposed to direct sunlight while flowers on the bottom part of the plant were under the leaf canopy and received indirect sunlight. Heat tolerance-related parameters including pollen germination (PG), pollen viability (PV), and cell membrane thermostability (CMT) were assessed under in vitro conditions while boll retention and boll weight were measured in vivo.

Flowers that showed dehiscence of anthers were collected from the field and immediately transported to the laboratory where pollen grains were deposited on pollen germination media. The media was prepared following the method explained by Burke et al. [9] with little modifications. The solid germination medium consisted of $2 \%(w / v)$ agarose (Product no. A4718, Sigma Aldrich, Merck, Darmstadt Germany), 25\% (w/v) sucrose (Product no. S0389, Sigma Aldrich, Merck, Germany), $0.52 \mathrm{mM} \mathrm{KNO}_{3}$ (Product no. P8291, Sigma Aldrich, Merck, Darmstadt Germany), 3.06 mM MnSO 4 (Product no. M7899, Sigma Aldrich, Merck, Darmstadt Germany), $1.66 \mathrm{mM} \mathrm{H}_{3} \mathrm{BO}_{3}$ (Product no. B6768, Sigma Aldrich, Merck, Darmstadt Germany), $0.42 \mathrm{mM} \mathrm{MgSO} \cdot 7 \mathrm{H}_{2} \mathrm{O}$ (Product no. M2643, Sigma Aldrich, Merck, Darmstadt Germany) and $1.0 \mu \mathrm{M} \mathrm{A}_{3}$ gibberellic acid (Product no. G7645, Sigma Aldrich, Merck, Darmstadt Germany). The $\mathrm{pH}$ of the germination medium was brought to 7.6 before adding sucrose and agarose. The medium was autoclaved and poured into Petri plates $(100 \times 15 \mathrm{~mm}$, Product no. P5856, Sigma Aldrich, Merck, Darmstadt Germany) under a laminar flow hood to avoid contamination. Plates were wrapped with cling 
film tape then placed in a refrigerator until used. Pollen grains with pollen tube lengths greater than the diameter of the pollen grains themselves were considered to be germinated (Figure 1). Percent pollen germination was estimated using the following equation:

$$
\text { Pollen germination }(\%)=\frac{\text { Number of germinated pollen grains }}{\text { Total number of pollen grains }} \times 100
$$

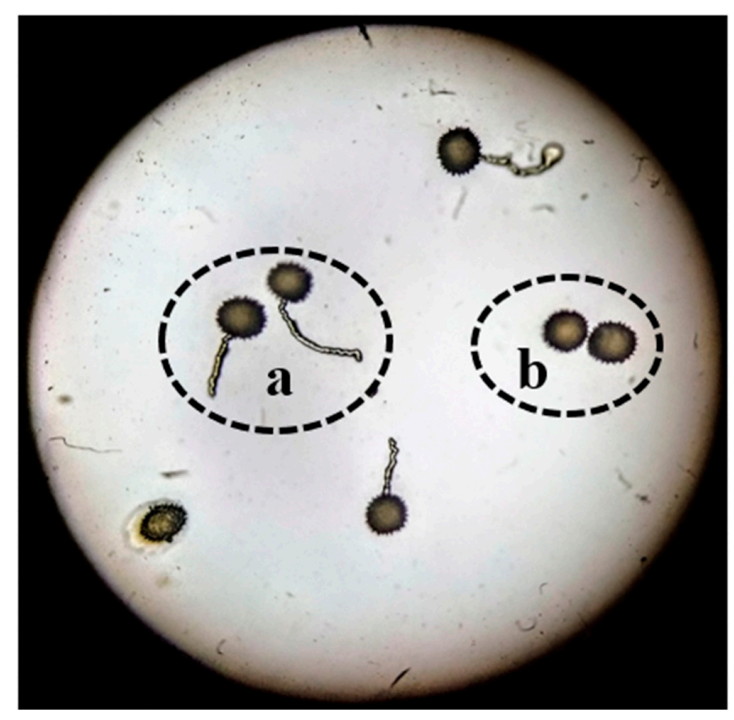

Figure 1. An example of pollen tube growth. A pollen grain that has germinated its pollen tube is labeled as ' $a$ ' while non-germinating pollen grains are labeled as ' $b$ '.

The triphenyl-tetrazolium chloride (TTC) test was used to test the viability of pollen grains [26]. Flowers that showed dehiscence of anthers were taken into the laboratory to test pollen viability. Fresh pollen grains were sprinkled on a glass slide $(76 \times 26 \mathrm{~mm})$ by gently tapping the flower. Two to three drops of $0.5 \%$ 2,3,5-triphenyl tetrazolium chloride (Product no. 17779, Millipore, Merck, Germany) were added in a $15 \%$ sucrose solution (Product no. S0389, Sigma Aldrich, Merck, Germany). The slide was covered with a coverslip $(20 \times 20 \mathrm{~mm})$ to prevent desiccation and then placed under sunlight for $60 \mathrm{~min}$ at 30-37 ${ }^{\circ} \mathrm{C}$. After this exposure, slides were observed under a light microscope (Model XSZ 107BN, Manufacturer: Zenith Lab Inc., Zhejiang China). The pollen grains that changed to red color after exposure to the TTC solution were considered viable while non-viable pollen remained yellowish in color (Figure 2). Pollen viability percentage was estimated using the following equation:

$$
\text { Pollen viability }(\%)=\frac{\text { Number of viable pollen grains }}{\text { Total number of pollen grains }} \times 100
$$

Two leaves from the top of the plant and two leaves from the bottom of the plant were selected for measuring CMT following the protocol of Sullivan [27] and using the following equation:

$$
\text { Cell membrane thermostability }(\%)=\left[\frac{1-\mathrm{T}_{1} / \mathrm{T}_{2}}{1-\mathrm{C}_{1} / \mathrm{C}_{2}}\right] \times 100
$$

where, the subscripts 1 and 2 refer to the 1st and 2nd electrical conductivity (EC) readings, respectively, and $\mathrm{T}$ and $\mathrm{C}$ refer to the EC of heat-treated (T) and control (C) sets of test tubes. The EC value was measured by a portable EC meter (FieldScout EC 110 Meter).

Boll weight, boll retention percentage, chlorophyll content, and canopy temperature were measured at harvest. For boll weight, all bolls from plants within the plot were harvested and weighed using an analytical balance (least count $=0.01 \mathrm{~g}$ ). Total boll weight 
was divided by the total number of selected bolls to get the average weight of an individual boll. Boll retention percentage was estimated as the number of fruiting positions on the plant that had bolls divided by the total number of fruiting positions. To measure boll retention, all fruiting squares were labeled 60 days after sowing (DAS). One hundred days after sowing, the number of labeled bolls was counted. Boll retention was calculated as follows:

$$
\text { Boll retention }=\frac{\text { Number of labeled bolls 100 DAS }}{\text { Number of labeled fruiting squares 60 DAS }} \times 100
$$

The leaf chlorophyll content was measured using a "SPAD 502 Plus" (Konica Minolta, Japan) chlorophyll meter which works on the principle of red and blue light absorption (therefore, the SPAD measurement has no units). Top and bottom canopy temperatures of upland cotton genotypes was measured using an infrared crop temperature meter (Model: 2956, Spectrum technologies, Inc., Plainfield, NJ, USA) at crop maturity (Table 2).

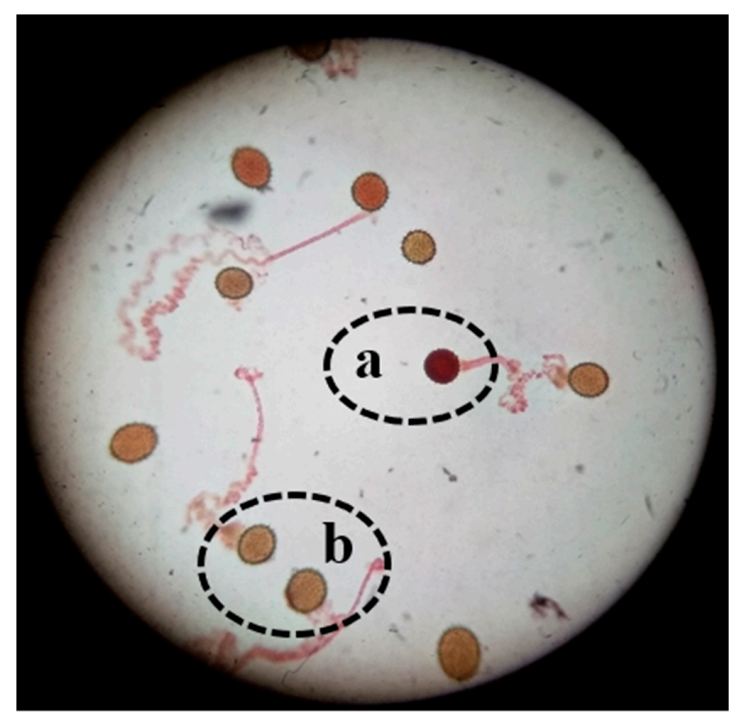

Figure 2. An example of results from the triphenyl-tetrazolium chloride (TTC) test. Viable pollen has changed to a red color (labeled as ' $a$ ') while non-viable pollen does not change color (labeled as ' $b$ ').

Table 2. Top and bottom canopy temperature in 13 cotton genotypes grown under field conditions in 2019 in Faisalabad, Pakistan.

\begin{tabular}{ccc}
\hline Genotypes & Top Temp. $\left({ }^{\circ} \mathbf{C}\right)$ & Bottom Temp. $\left({ }^{\circ} \mathbf{C}\right)$ \\
\hline CRS-2 & 35 & 33 \\
VH-377 & 37 & 36 \\
FH-215 & 35 & 33 \\
CIM-343 & 37 & 35 \\
CIM-602 & 35 & 34 \\
MNH-1016 & 34 & 32 \\
MNH-1026 & 35 & 33 \\
NIBGE-2 & 36 & 34 \\
N-777 & 37 & 35 \\
N-1048 & 35 & 33 \\
CYTO-124 & 35 & 33 \\
CYTO-608 & 36 & 34 \\
AA-933 & 36 & 35 \\
\hline
\end{tabular}

\subsection{Data Analysis}

Analysis of variance was conducted with replication, genotype, and position as main effects. The interaction effect of genotype and position was also analyzed to identify sources 
of variation [28]. Statistix 8.1 (An Software, 2003) was used to calculate ANOVA and Tukey's test [29]. Tukey's test was applied to test the significant difference of variation between the cotton genotypes and variation between the two positions for selected traits [30]. Cluster analysis was carried out using the statistical software package of Minitab ver.17.

\section{Results}

Genotypes were significantly different for all recorded parameters, and plant position was also significantly different for all parameters except boll weight (Table 3). Of the sources of variation, plant position had the largest effect on PV, PG, chlorophyll content, and boll retention. The effect of genotype was largest for the cell membrane thermostability and boll weight parameters. The mean values for each measure of heat tolerance in the top and bottom plant positions of the genotypes are provided in Table 4.

Table 3. Mean squares for six measures of heat tolerance in cotton grown under field conditions.

\begin{tabular}{cccccccc}
\hline Source of Variation & DF & PV & PG & Chl. Cont. & CMT & Boll Wt. & Boll Ret. \\
\hline Replication & 2 & $166.88^{* *}$ & $51.50^{\mathrm{NS}}$ & $46.67^{\mathrm{NS}}$ & $10.14^{\mathrm{NS}}$ & $0.13^{\mathrm{NS}}$ & $2.79^{\mathrm{NS}}$ \\
Genotype & 12 & $199.58^{* *}$ & $173.82^{* *}$ & $1218.46^{* *}$ & $3142.60^{* *}$ & $0.80^{* *}$ & $18.10^{* *}$ \\
Position & 1 & $1456.01^{* *}$ & $873.35^{* *}$ & $1813.86^{* *}$ & $2807.12^{* *}$ & $0.28^{\mathrm{NS}}$ & $304.88^{* *}$ \\
Genotype $\times$ Position & 12 & $19.37^{\mathrm{NS}}$ & $6.18^{\mathrm{NS}}$ & $65.06^{\mathrm{NS}}$ & $91.64^{* *}$ & $0.10^{\mathrm{NS}}$ & $6.41^{\mathrm{NS}}$ \\
Error & 50 & 21.02 & 26.83 & 41.93 & 30.79 & 0.09 & $6.27^{2}$ \\
Total & 77 & & & & & &
\end{tabular}

** $p<0.01$ and NS = Nonsignificant; DF = Degree of freedom; PV = Pollen viability; PG = Pollen germination; Chl. Cont. = Chlorophyll content; $\mathrm{CMT}=$ Cell membrane thermostability; Boll Wt. = Boll weight; Boll Ret. = Boll retention.

Table 4. Mean values with standard errors for six measures of heat tolerance in the top and bottom positions of 13 cotton genotypes grown in 2019 in Faisalabad, Pakistan.

\begin{tabular}{|c|c|c|c|c|c|c|c|}
\hline Genotypes & Positions & PV (\%) & PG (\%) & Chl. Cont. & СMT (\%) & Boll Wt. (g) & Boll Ret. (\%) \\
\hline \multirow{2}{*}{ CRS-2 } & Top & $30.33 \pm 2.03$ & $24.00 \pm 2.31$ & $47.70 \pm 3.65$ & $73.80 \pm 4.91$ & $3.14 \pm 0.09$ & $29.11 \pm 2.73$ \\
\hline & Bottom & $34.33 \pm 2.33$ & $28.67 \pm 2.96$ & $50.87 \pm 3.88$ & $88.75 \pm 5.95$ & $3.30 \pm 0.17$ & $36.45 \pm 0.75$ \\
\hline \multirow{2}{*}{ VH-377 } & Top & $25.33 \pm 2.91$ & $14.67 \pm 3.18$ & $62.20 \pm 2.11$ & $78.68 \pm 2.52$ & $2.80 \pm 0.20$ & $30.51 \pm 0.26$ \\
\hline & Bottom & $33.00 \pm 4.36$ & $21.00 \pm 1.73$ & $72.37 \pm 3.46$ & $86.61 \pm 1.61$ & $3.30 \pm 0.07$ & $32.48 \pm 0.85$ \\
\hline \multirow{2}{*}{ FH-215 } & Top & $26.67 \pm 1.45$ & $17.67 \pm 3.18$ & $48.80 \pm 2.93$ & $72.81 \pm 0.94$ & $2.61 \pm 0.15$ & $28.97 \pm 2.20$ \\
\hline & Bottom & $31.33 \pm 2.03$ & $25.67 \pm 2.85$ & $65.40 \pm 2.95$ & $75.95 \pm 2.21$ & $2.84 \pm 0.06$ & $32.88 \pm 2.73$ \\
\hline \multirow{2}{*}{ CIM-343 } & Top & $23.33 \pm 0.88$ & $15.00 \pm 2.65$ & $51.20 \pm 1.95$ & $72.53 \pm 4.36$ & $3.26 \pm 0.08$ & $24.85 \pm 1.19$ \\
\hline & Bottom & $32.00 \pm 1.15$ & $23.00 \pm 4.16$ & $60.23 \pm 2.45$ & $79.39 \pm 1.79$ & $3.40 \pm 0.11$ & $30.79 \pm 1.27$ \\
\hline \multirow{2}{*}{ CIM-602 } & Top & $21.00 \pm 1.73$ & $17.00 \pm 1.15$ & $96.90 \pm 4.39$ & $81.68 \pm 3.48$ & $2.19 \pm 0.06$ & $26.79 \pm 1.92$ \\
\hline & Bottom & $31.00 \pm 4.16$ & $22.33 \pm 1.20$ & $103.8 \pm 2.39$ & $91.31 \pm 1.19$ & $2.36 \pm 0.16$ & $31.34 \pm 0.28$ \\
\hline \multirow{2}{*}{ MNH-1016 } & Top & $21.00 \pm 1.73$ & $10.33 \pm 1.86$ & $50.10 \pm 4.72$ & $88.67 \pm 2.56$ & $2.45 \pm 0.19$ & $30.53 \pm 2.24$ \\
\hline & Bottom & $28.67 \pm 2.03$ & $15.67 \pm 2.03$ & $56.37 \pm 2.86$ & $92.50 \pm 0.74$ & $2.71 \pm 0.08$ & $32.01 \pm 2.11$ \\
\hline \multirow{2}{*}{ MNH-1026 } & Top & $29.67 \pm 1.67$ & $19.00 \pm 3.06$ & $55.20 \pm 3.02$ & $83.19 \pm 0.50$ & $2.50 \pm 0.13$ & $30.21 \pm 1.27$ \\
\hline & Bottom & $43.00 \pm 3.61$ & $25.33 \pm 5.78$ & $60.25 \pm 3.01$ & $88.82 \pm 1.98$ & $2.36 \pm 0.20$ & $31.95 \pm 0.29$ \\
\hline \multirow{2}{*}{ NIBGE-2 } & Top & $19.00 \pm 2.08$ & $10.00 \pm 1.53$ & $51.27 \pm 2.59$ & $18.24 \pm 2.98$ & $2.58 \pm 0.24$ & $27.07 \pm 1.32$ \\
\hline & Bottom & $31.67 \pm 3.48$ & $16.00 \pm 2.08$ & $57.63 \pm 1.87$ & $32.54 \pm 3.51$ & $2.42 \pm 0.24$ & $32.17 \pm 0.66$ \\
\hline \multirow{2}{*}{ N-777 } & Top & $30.33 \pm 3.18$ & $17.67 \pm 3.93$ & $55.80 \pm 5.42$ & $78.88 \pm 4.63$ & $2.77 \pm 0.33$ & $29.16 \pm 1.43$ \\
\hline & Bottom & $38.33 \pm 3.28$ & $23.33 \pm 3.18$ & $61.50 \pm 4.85$ & $88.16 \pm 0.65$ & $2.63 \pm 0.09$ & $34.42 \pm 0.20$ \\
\hline \multirow{2}{*}{ N-1048 } & Top & $36.00 \pm 2.89$ & $9.00 \pm 2.08$ & $51.87 \pm 1.30$ & $41.47 \pm 3.46$ & $2.22 \pm 0.26$ & $24.08 \pm 1.47$ \\
\hline & Bottom & $39.67 \pm 2.91$ & $12.67 \pm 2.40$ & $74.67 \pm 4.64$ & $70.03 \pm 2.81$ & $1.83 \pm 0.05$ & $30.35 \pm 0.91$ \\
\hline \multirow{2}{*}{ CYTO-124 } & Top & $26.67 \pm 4.26$ & $17.67 \pm 1.76$ & $45.70 \pm 5.23$ & $22.95 \pm 2.78$ & $2.49 \pm 0.16$ & $31.71 \pm 0.87$ \\
\hline & Bottom & $42.00 \pm 5.51$ & $29.00 \pm 5.03$ & $51.99 \pm 4.56$ & $36.99 \pm 2.66$ & $2.76 \pm 0.09$ & $33.72 \pm 0.91$ \\
\hline \multirow{2}{*}{ СYTO-608 } & Top & $40.33 \pm 4.26$ & $22.00 \pm 2.65$ & $70.93 \pm 2.86$ & $83.47 \pm 2.90$ & $2.34 \pm 0.13$ & $28.35 \pm 1.11$ \\
\hline & Bottom & $47.00 \pm 4.04$ & $31.00 \pm 3.79$ & $87.13 \pm 7.27$ & $92.35 \pm 1.47$ & $2.58 \pm 0.22$ & $30.69 \pm 0.90$ \\
\hline \multirow{2}{*}{ AA-933 } & Top & $32.67 \pm 1.76$ & $24.00 \pm 3.06$ & $68.00 \pm 2.09$ & $83.88 \pm 2.50$ & $2.38 \pm 0.11$ & $30.17 \pm 1.72$ \\
\hline & Bottom & $42.67 \pm 1.45$ & $31.33 \pm 4.06$ & $78.83 \pm 4.42$ & $92.87 \pm 2.70$ & $2.77 \pm 0.40$ & $33.64 \pm 0.56$ \\
\hline
\end{tabular}

$\mathrm{PV}=$ Pollen viability; $\mathrm{PG}=$ Pollen germination; Chl. Cont. = Chlorophyll content; CMT = Cell membrane thermostability; Boll Wt. = Boll weight; Boll Ret. $=$ Boll retention. 


\subsection{Physiological Traits}

The viability and germination of pollen grains were higher in the bottom part of the plant as compared to pollen that developed in flowers on the top part of the plant (Figure 3). The maximum viability of pollen grains in the bottom position was seen in CYTO-608 (47\%) followed by MNH-1026 (43\%), and the lowest value was observed in MNH-1016 (28.67\%). The top flowers of CYTO-608 shown in Figure 4 and N-1048 showed the highest pollen viability measures of $40.33 \%$ and $36 \%$, respectively, while MNH-1016 and CIM-602 had the lowest pollen viability of $21 \%$ for both genotypes (Table 4). Tukey's mean comparison test for pollen viability revealed non-significant differences for the genotypes CYTO-608, $\mathrm{N}-1048$, and AA-933. On average, these genotypes performed well in both top and bottom positions (Table 5). Mean values of pollen viability across all genotypes to compare top and bottom positions of plants revealed a significant difference between top and bottom positions. Pollen viability at the bottom position exhibited more value compared to the top position (Figure 3).
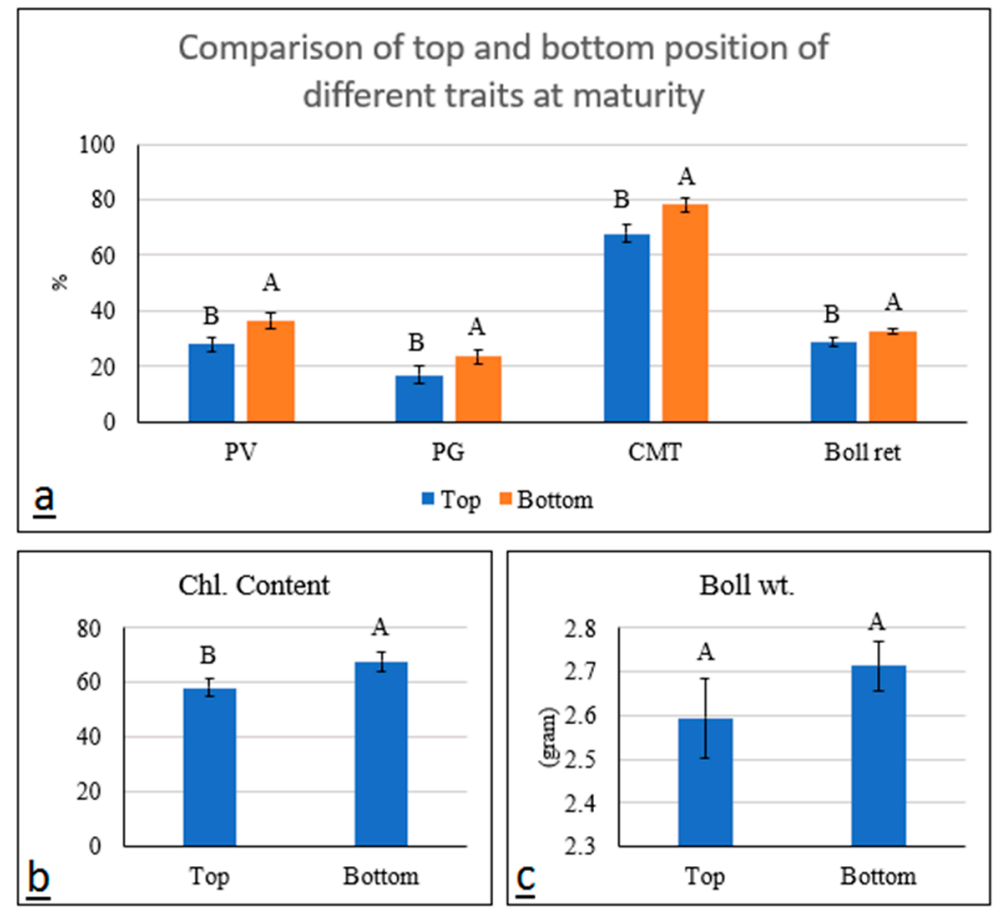

Figure 3. Means averaged across all genotypes to compare top and bottom positions of plants for different traits at maturity. The error bars are standard errors. The letters show Tukey's mean comparison where different letters show significant differences between top and bottom positions for each trait. (a) PV (Pollen viability), PG (Pollen germination), CMT (Cell membrane thermostability) and boll ret (boll retention), (b) Chl. Content (Chlorophyll content), (c) Boll wt (Boll weight).

The highest pollen germination from flowers at the bottom position was observed in AA-933 (31.33\%) while in the top position, both AA-933 and CRS- 2 showed $24 \%$ pollen germination. The lowest value for this parameter was observed in $\mathrm{N}-1048$ with $12.67 \%$ and $9 \%$ germination in the bottom and top positions, respectively (Table 4). Overall, pollen from flowers that bloomed on top parts of the plant showed less germination when compared to pollen from bottom flowers (Figure 3). Pollen germination estimates were also lower than pollen viability estimates. Tukey's mean test revealed a non-significant difference between CRS-2, Cyto-608, and AA-933. It was observed that these genotypes performed well in both viability and germination tests, except CRS-2 which showed good pollen germination (Table 5). This indicates that most of the viable pollen of CRS-2 did germinate. Variation in pollen tube length was also observed as shown in Figure 5. 

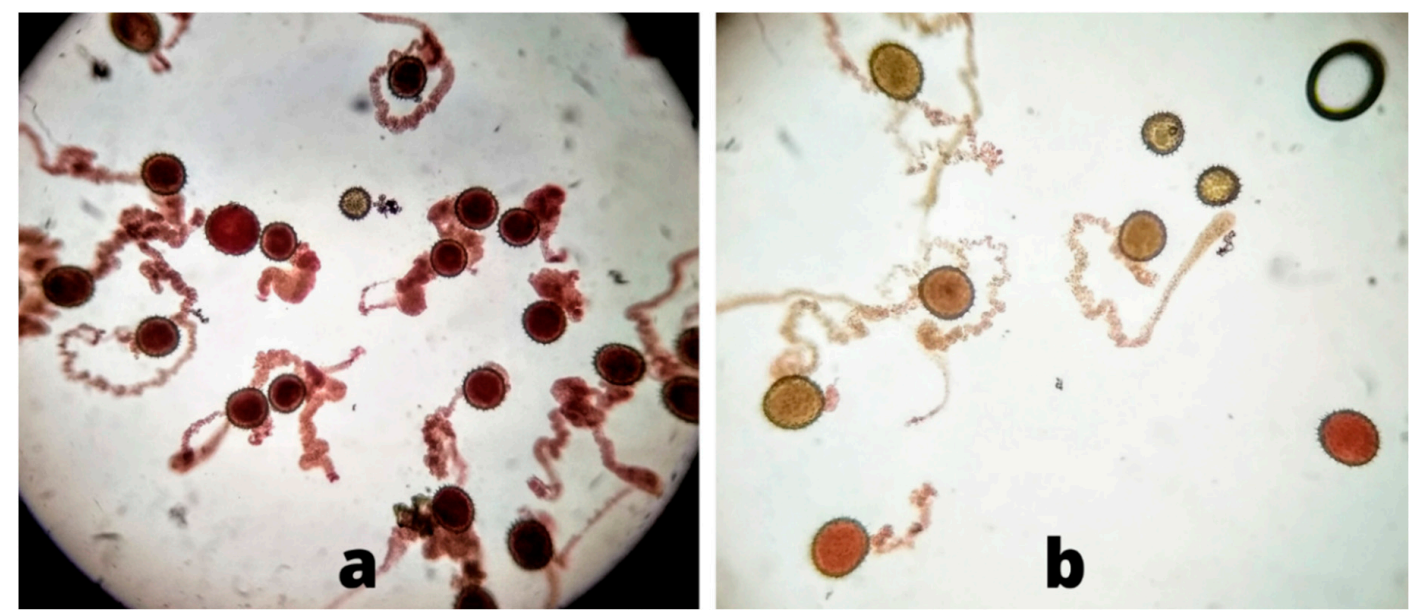

Figure 4. Results from staining pollen with triphenyl-tetrazolium chloride (TTC). (a) Pollen from flowers from the bottom positions of CYTO-608 shows the highest pollen viability. (b) Pollen from flowers from the top positions of NIBGE-2 shows the lowest pollen viability.

Table 5. Mean values for six measures of heat tolerance in 13 cotton genotypes grown in 2019 in Faisalabad, Pakistan.

\begin{tabular}{ccccccc}
\hline Genotypes & PV (\%) & PG (\%) & Chl. Cont. & CMT (\%) & Boll Wt. (g) & Boll Ret. (\%) \\
\hline CRS-2 & $32.33^{\mathrm{BCDE}}$ & $26.33^{\mathrm{A}}$ & $49.28^{\mathrm{F}}$ & $81.28^{\mathrm{ABC}}$ & $3.21^{\mathrm{AB}}$ & $32.78^{\mathrm{A}}$ \\
VH-377 & $29.17^{\mathrm{BCDE}}$ & $17.83^{\mathrm{ABC}}$ & $67.28^{\mathrm{BCD}}$ & $82.64^{\mathrm{ABC}}$ & $3.05^{\mathrm{ABC}}$ & $31.50^{\mathrm{AB}}$ \\
FH-215 & $29.00^{\mathrm{BCDE}}$ & $21.67^{\mathrm{AB}}$ & $57.10^{\mathrm{DEF}}$ & $74.38^{\mathrm{C}}$ & $2.73^{\mathrm{ABCD}}$ & $30.92^{\mathrm{AB}}$ \\
CIM-343 & $27.67^{\mathrm{CDE}}$ & $19.00^{\mathrm{ABC}}$ & $55.72^{\mathrm{DEF}}$ & $75.96^{\mathrm{BC}}$ & $3.33^{\mathrm{A}}$ & $27.82^{\mathrm{AB}}$ \\
CIM-602 & $26.00^{\mathrm{DE}}$ & $19.67^{\mathrm{ABC}}$ & $100.35^{\mathrm{A}}$ & $86.64^{\mathrm{A}}$ & $2.27^{\mathrm{DE}}$ & $28.57^{\mathrm{AB}}$ \\
MNH-1016 & $24.83^{\mathrm{E}}$ & $13.00^{\mathrm{BC}}$ & $53.23^{\mathrm{EF}}$ & $90.59^{\mathrm{A}}$ & $2.58^{\mathrm{CDE}}$ & $31.27^{\mathrm{AB}}$ \\
MNH-1026 & $36.33^{\mathrm{ABC}}$ & $22.17^{\mathrm{AB}}$ & $57.73^{\mathrm{DEF}}$ & $86.01^{\mathrm{AB}}$ & $2.43^{\mathrm{DE}}$ & $31.08^{\mathrm{AB}}$ \\
NIBGE-2 & $25.33^{\mathrm{DE}}$ & $13.00^{\mathrm{BC}}$ & $54.45^{\mathrm{DEF}}$ & $25.39^{\mathrm{E}}$ & $2.50^{\mathrm{CDE}}$ & $29.62^{\mathrm{AB}}$ \\
N-777 & $34.33^{\mathrm{BCD}}$ & $20.50^{\mathrm{ABC}}$ & $58.65^{\mathrm{CDEF}}$ & $85.61^{\mathrm{AB}}$ & $2.69^{\mathrm{BCD}}$ & $31.79^{\mathrm{AB}}$ \\
N-1048 & $37.83^{\mathrm{AB}}$ & $10.83^{\mathrm{C}}$ & $65.35^{\mathrm{CDE}}$ & $55.75^{\mathrm{D}}$ & $2.03^{\mathrm{E}}$ & $31.96^{\mathrm{AB}}$ \\
CYTO-124 & $34.33^{\mathrm{BCD}}$ & $23.33^{\mathrm{AB}}$ & $48.85^{\mathrm{F}}$ & $29.97^{\mathrm{E}}$ & $2.62^{\mathrm{BCDE}}$ & $32.67^{\mathrm{AB}}$ \\
CYTO-608 & $43.67^{\mathrm{A}}$ & $26.50^{\mathrm{A}}$ & $79.03^{\mathrm{B}}$ & $85.81^{\mathrm{AB}}$ & $2.46^{\mathrm{CDE}}$ & $29.52^{\mathrm{AB}}$ \\
AA-933 & $37.67^{\mathrm{AB}}$ & $27.67^{\mathrm{A}}$ & $71.33^{\mathrm{BC}}$ & $88.38^{\mathrm{A}}$ & $2.58^{\mathrm{CDE}}$ & $27.71^{\mathrm{B}}$ \\
\hline
\end{tabular}

$\mathrm{PV}=$ Pollen viability; $\mathrm{PG}=$ Pollen germination; Chl. Cont. = Chlorophyll content; $\mathrm{CMT}=$ Cell membrane thermostability; Boll Wt. = Boll weight; Boll Ret. = Boll retention. Means with the same letters in each column are not significantly different according to Tukey's test.
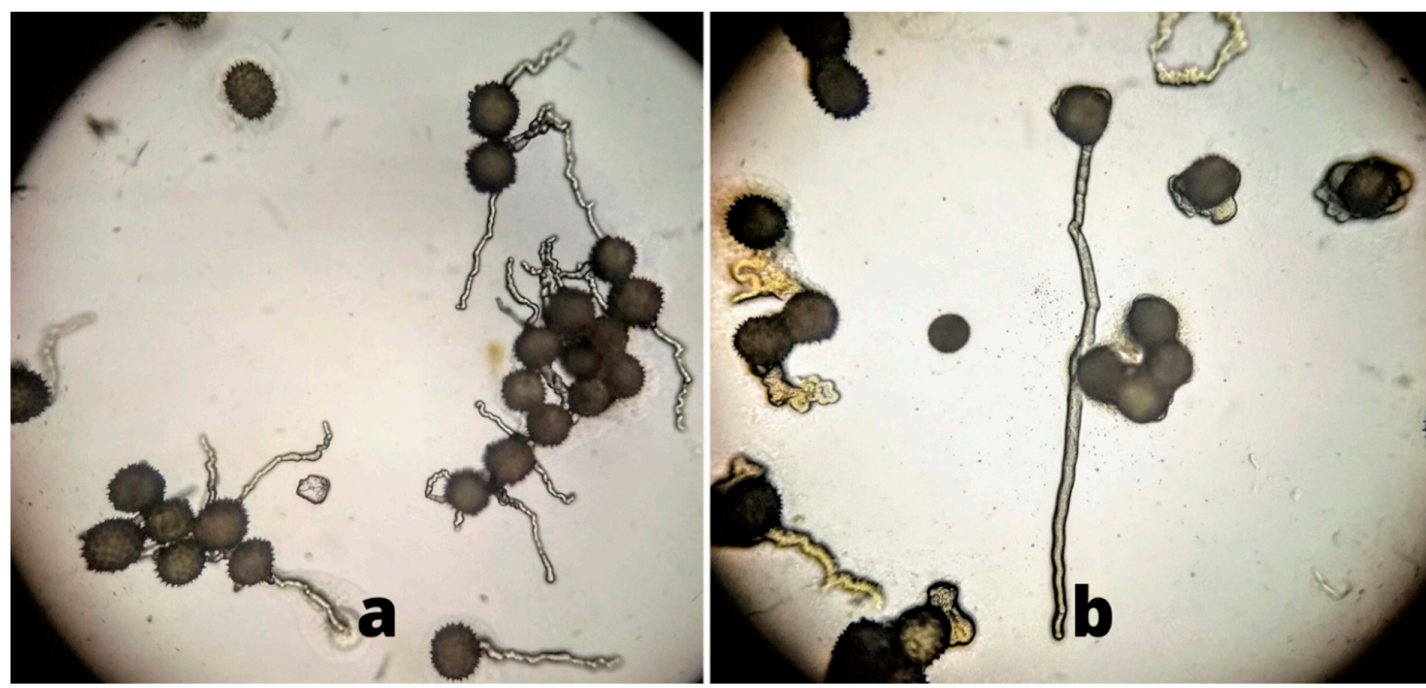

Figure 5. The observed variation in pollen tube germination where (a) Bottom flowers from AA-933 showed maximum pollen germination (b) Top flowers from N-1048 showed lowest pollen germination. 
Cell membrane thermostability (CMT) and chlorophyll content were also significantly different for genotypes and plant positions (Table 3). The CMT values for top leaves $(67.96 \%)$ were lower than values for bottom leaves $(78.17 \%)$ (Figure 3). At the bottom of the plant, the maximum value for CMT was recorded for the genotype AA-933 (92.87\%) followed by MNH-1016, CYTO-608, and CIM-602 which presented $92.50 \%, 92.35 \%$, and 92.31\% CMT, respectively (Table 4). Leaves of the bottom branches had more chlorophyll content as compared to leaves from the top branches (Figure 3). The genotypes CIM-602, CYTO-608, and AA-933 showed the highest chlorophyll contents in bottom branches (103.8, 87.13 , and 78.83, respectively) while CIM-602 also had the highest chlorophyll content in leaves of top branches (96.9) (Table 4).

\subsection{Morphological Traits}

Genotypes varied significantly for boll weight, but non-significant differences were observed between the top and bottom plant portions for this trait (Table 3). On average, the largest boll weight at the bottom position was observed for CIM-343 (3.40 g) followed by CRS-2 and VH-377 (3.30 g for each) while N-1048 exhibited the lowest boll weight (Table 4). Tukey's test revealed non-significant differences among CIM-343, CRS-2, and VH-377 genotypes for boll weight (Table 5). Boll retention percentage was significantly different for genotypes and positions (Table 3). Lower boll retention was observed in the top position branches as compared to bottom branches (Figure 3). In the bottom branches, the genotype CRS-2 had maximum boll retention (36.45\%) followed by N-777 $(34.42 \%)$ and CYTO-124 (33.72\%). The minimum boll retention was observed in N-1048 for both portions of the plant. Boll retention was also low in the top branches of CIM-343 (Table 4). It was noted that genotypes with high pollen germination retained more bolls.

\subsection{Cluster Analysis}

All the genotypes were clustered using pollen germination, pollen viability, cell membrane thermostability, chlorophyll content, boll weight, and boll retention at hightemperature stress as variables. The dendrogram showed three clusters with a minimum of $33.33 \%$ similarity level. The highest Euclidean distance was found between clusters 2 and 3 (57.76) and lowest between clusters 1 and 2 (27.95) as presented in Table 6.

Table 6. The distance among the various cluster centroid of cotton genotypes under high temperature.

\begin{tabular}{lccc}
\hline & Cluster 1 & Cluster 2 & Cluster 3 \\
\hline Cluster 1 & 0 & 27.9541 & 45.5783 \\
Cluster 2 & & 0 & 57.7641 \\
Cluster 3 & & & 0 \\
\hline
\end{tabular}

The clusters were divided into two groups Group Y and Group Z. Group Y included two clusters named cluster 1 and cluster 2 while Group $Z$ included only one cluster named cluster 3. Cluster 1 included seven genotypes named CRS-2, MNH-1026, N-777, MNH1016, VH-377, FH-215, and CIM-343 which represent $53.85 \%$ of total genotypes. Cluster 2 includes three genotypes named CIM-602, Cyto-608 and AA-933 represent $23.07 \%$ of total genotypes. In cluster 3, three genotypes are included named NIBGE-2, Cyto-124, and $\mathrm{N}-1048$ representing $23.07 \%$ of the total genotype (Figure 6). The genotypes within each cluster exhibited similar behavior based on six traits used in this study. The genotypes in cluster 1 showed good performance based on boll weight. The genotypes grouped in cluster 2 are characterized by high pollen germination, pollen viability, chlorophyll content, and CMT. This indicated that the genotypes grouped in cluster 2 could be selected for the breeding program. The genotypes of cluster 3 were grouped by the lowest value of pollen germination, pollen viability, CMT, and boll weight (Table 7). 


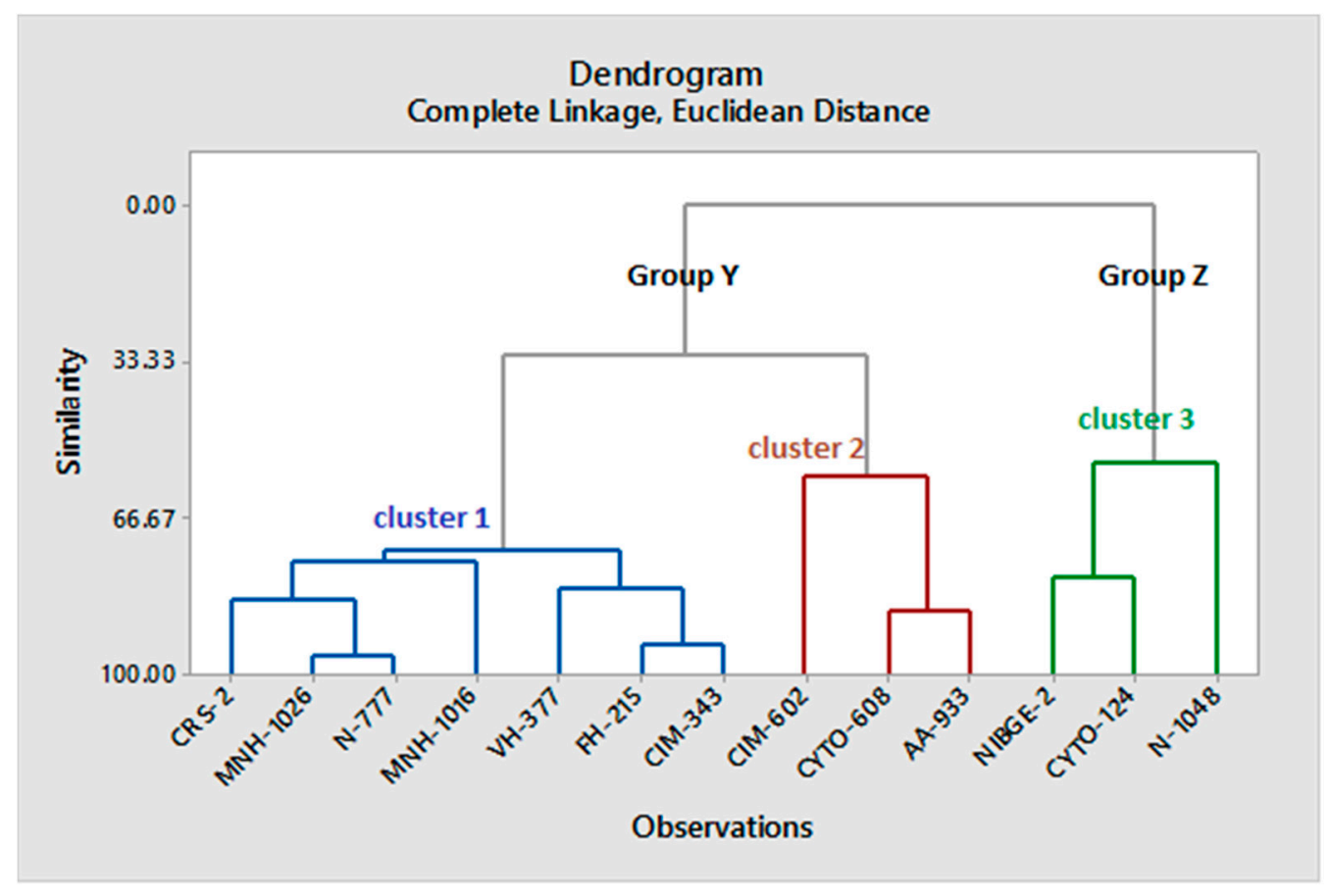

Figure 6. Cluster analysis of thirteen accessions of upland cotton evaluated for high-temperature regimes.

Table 7. Means of clusters of 13 cotton genotypes of all observed tr under high-temperature stress.

\begin{tabular}{lcccc}
\hline Variable & Cluster $\mathbf{1}$ & Cluster $\mathbf{2}$ & Cluster 3 & Grand Centroid \\
\hline No. of genotypes & 7 & 3 & 3 & 13 \\
PV (\%) & 30.5229 & 35.78 & 32.4967 & 32.1915 \\
PG (\%) & 20.0714 & 24.6133 & 15.72 & 20.1154 \\
Chl. Cont. & 56.9986 & 83.57 & 56.2167 & 62.95 \\
CMT (\%) & 82.3529 & 86.9433 & 37.0367 & 72.9546 \\
Boll Wt. (g) & 2.86 & 2.4367 & 2.3833 & 2.6523 \\
Boll Ret. $(\%)$ & 31.0229 & 28.6 & 31.4167 & 30.5546 \\
\hline
\end{tabular}

\section{Discussion}

Higher pollen germination and viability percentages from flowers under the canopy of the plant as compared to flowers in direct sunlight were observed in this study. As the temperature in the experimental region in Pakistan rises to $47^{\circ} \mathrm{C}$ during the time of cotton flowering, this damages the lipid as well as protein parts of the pollen membrane, thus resulting in decreases in pollen viability [12]. Pollen viability was determined by analyzing dehydrogenase enzyme activity in the pollen grains-if the enzyme is active, viable pollen grains change to a red color after TTC staining. However, there may be damage to the pollen grains that reduces germination despite this enzyme activity. It has been reported that the distribution of cell organelles such as mitochondria, vacuoles, and endoplasmic reticulum of pollen cells become disturbed under high temperatures. Lipid and starch granules are also reduced in pollen cells during heat stress [8].

In our study, lower pollen germination was observed as compared to pollen viability. Most pollen could not develop the pollen tube required for germination, likely due to metabolic or structural abnormalities of pollen grains [31]. Drought or heat stress significantly lowers carbohydrate metabolism in the pistil, resulting in a lower energy supply to the pollen tube in the style, thus leading to a failure of fertilization [32]. Under excessively high temperatures, heat shock proteins (HSPs) work to stabilize proteins that were damaged when exposed to stressful conditions. As the expression of HSPs varies between genotypes, some genotypes showed good pollen germination even in the top portion of the plant [33]. 
Genotypic variability for CMT has been previously reported [3,34]. Here, we have observed CMT differences between plant positions. The significant differences among cultivars are due to several factors including cuticle thickness, secondary metabolites, and heat shock proteins [35-37]. Lower CMT estimates in top leaves were due to sunlight exposure. The membranes of leaves facing direct sunlight in high-temperature conditions were more prone to damage. Sun rays cause oxidative damages to both lipid and protein parts of the cellular membranes and cause the leakage of electrolytes [38]. UV radiation from the sun causes irreversible damage to plant pigments [39]. It causes conformational changes in the structure of nucleic acids, proteins, and macromolecules in the cell and degrades the chlorophyll pigment $[40,41]$. Heat stress directly affects the flow of fluid through the cell membrane as relative electrical conductivity increases with temperature $[42,43]$.

Since the chlorophyll contents under the canopy were higher as compared to the top position, it has been assumed that chlorophyll loses its integrity under direct sunlight. In addition to direct sunlight, the higher temperature in the top portion of the plant also causes chlorophyll damage [44]. Heat stress that denatures thylakoid membranes results in a loss of chlorophyll [45]. Moreover, the enzymes required for the synthesis of chlorophyll and its normal activity were also denatured under high-temperature conditions [46]. As a result, photosynthetic activity was reduced in the top portion of plants. On average, the genotypes AA-933 and CYTO-608 had good heat tolerance features in bottom positions; therefore, these genotypes would be useful as parents in a breeding program

Ascorbic acid has the potential to mitigate the negative effects of stress. It acts in ROS scavenging and maintains the integrity of membranes, including the thylakoid membrane [47]. So, ascorbic acid could be used to overcome the heat stress problem. The cell membrane thermostability of cotton crops can be improved significantly by applying the foliar application of $40 \mathrm{mg} \mathrm{L}^{-1}$ ascorbic acid [48].

Boll weight is positively associated with seed cotton yield. It is a complex polygenic trait that depends upon numerous factors namely, the weight of seed, seed size, protein and oil content within the seed, and cellulose deposition during fiber development and maturity [49]. It is one of the most important characters linked to improved yield, and significant variation for this trait has been reported in germplasm [50,51]. Although the genotypes used in this experiment were significantly different for boll weight, no significant differences for this trait were recorded between the top and bottom portions of the same genotypes. Retention of bolls during the developmental period varied significantly between the top and bottom branches. The bottom branches tend to hold more bolls as compared to the top branches. It was noted that the genotypes with higher pollen viability and germination also retained more bolls. This study revealed that the heat tolerance ability of the genotypes was associated with boll retention while heat stress has been considered one of the major factors in bolls dropping before maturity $[52,53]$. Thus, high temperature in the top portion of a plant due to direct exposure to sunlight can explain retaining a lower number of bolls in this portion of the plant.

The variability was found between the genotypes as shown in Table 3. Cluster analysis has revealed that CIM-602, Cyto-608, and AA-933 grouped in cluster 2 performed well and these genotypes could be used further in any breeding program. Since all genotypes are grown in the Punjab region of Pakistan, these are therefore acclimatized to this environment. These genotypes share some common, as well as different phenotypes, which showed variability based on six traits used in this study. The variability was also observed in the cotton genotypes cultivated in the Punjab region of Pakistan by khan [54].

This study provides an understanding of the role of flowering in the top and bottom portions of the cotton plant in response to high-temperature stress because high temperature is a major factor in reducing yield. It is assumed that by increasing the vegetative growth and leaf surface area, the shading effect can be increased. The spreading-type behavior of the cotton plant could be able to produce more shading. The shading effect will reduce canopy temperature and hence yield could be increased. Likewise, screening for early maturing cultivars and for having more branches on the bottom part of the plant 
could be beneficial because the bottom branches have shown more productivity than top branches. Keeping in view the importance of the study, another study may be conducted to assess the temperature of the microenvironment i.e., the temperature of leaf, bud, and/or boll at the top and bottom regions of each genotype, followed by correlation analysis with each trait to understand the relationship of various traits during heat stress.

\section{Conclusions}

Both top and bottom branches of the cotton plant exhibited variable responses for physiological and morphological traits. Significant genotypic variability for these attributes was also observed. The bottom branches of the genotypes performed better for all the recorded parameters except boll weight which was non-significant for both positions. The high temperature was found to disrupt plant physiology and morphology more on top position flowers. Further study of the shading effect is an objective for future breeding programs. A focus on increasing vegetative growth, leaf surface area, and a more spreading growth pattern would increase the canopy size and allow for shading to improve pollen germination and pollen tube growth. Further, research focusing on increased resilience to high temperature itself would allow top portions of a cotton plant to deliver a higher yield thus increasing overall yields.

Author Contributions: Conceptualization, M.T.A., I.A.R. and S.-H.Y.; methodology, M.T.A., A.u.R., M.Z., M.T.C. and S.M.; software, A.u.R., X.D., Y.J.; validation, M.T.A., S.M. and I.A.R. formal analysis, A.u.R. and M.T.C.; investigation, M.T.A., L.H. and A.u.R.; data curation, M.Z. and A.u.R., writingoriginal draft preparation, A.u.R. and M.T.C. and S.M.; writing-review and editing, M.T.A., I.A.R., G.C., A.u.R., S.M. and L.H.; supervision, M.T.A.; funding acquisition, S.-H.Y. All authors have read and agreed to the published version of the manuscript.

Funding: This work was carried out with the support of "Basic Science Research Program through the National Research Foundation of Korea (NRF) funded by the Ministry of Education (NRF2021R1F1A10554820).

Institutional Review Board Statement: Not applicable.

Informed Consent Statement: Not applicable.

Acknowledgments: The authors are grateful to the Lab. Incharge for provision of necessary equipment and chemicals at the Center for Advanced Studies, University of Faisalabad (Pakistan). USDA is an equal opportunity provider and employer.

Conflicts of Interest: The authors declare no conflict of interest.

\section{References}

1. Dabbert, T.; Gore, M.A. Challenges and perspectives on improving heat and drought stress resilience in cotton. J. Cotton Sci. 2014, 18, 393-409.

2. Oosterhuis, D.M. Day or night high temperatures: A major cause of yield variability. Cotton Grow. 2002, 46, 8-9.

3. Abro, S.; Rajput, M.T.; Khan, M.A.; Sial, M.A.; Tahir, S.S. Screening of cotton (Gossypium hirsutum L.) genotypes for heat tolerance. Pak. J. Bot. 2015, 47, 2085-2091.

4. Salman, M.; Majeed, S.; Rana, I.A.; Atif, R.M.; Azhar, M.T. Novel breeding and biotechnological approaches to mitigate the effects of heat stress on cotton. In Recent Approaches in Omics for Plant Resilience to Climate Change; Wani, S., Ed.; Springer: Berlin/Heidelberg, Germany, 2019; pp. 251-277, ISBN 978-3-030-21686-3.

5. Snider, J.L.; Oosterhuis, D.M.; Skulman, B.W.; Kawakami, E.M. Heat-stress induced limitations to reproductive success in Gossypium hirsutum L. Physiol. Plant 2009, 137, 125-138. [CrossRef] [PubMed]

6. De Storme, N.; Geelen, D. The impact of environmental stress on male reproductive development in plants: Biological processes and molecular mechanisms. Plant Cell Environ. 2014, 37, 1-18. [CrossRef]

7. Snider, J.L.; Oosterhuis, D.M.; Kawakami, E.M. Diurnal pollen tube growth rate is slowed by high temperature in field-grown Gossypium hirsutum pistils. J. Plant Physiol. 2011, 168, 441-448. [CrossRef] [PubMed]

8. Song, G.; Chen, Q.; Tang, C. The effects of high-temperature stress on the germination of pollen grains of upland cotton during square development. Euphytica 2014, 200, 175-186. [CrossRef]

9. Burke, J.J.; Velten, J.; Oliver, M.J. In vitro analysis of cotton pollen germination. Agron. J. 2004, 96, 359-368. [CrossRef]

10. Foyer, C.H.; Bloom, A.; Queval, G.; Noctor, G. Photo respiratory metabolism: Genes, mutants, energetics and redox signaling. Annu. Rev. Plant. Biol. 2009, 60, 455-484. [CrossRef] 
11. Jiang, P.; Zhang, X.; Zhu, Y.; Zhu, W.; Xie, H.; Wang, X. Metabolism of reactive oxygen species in cotton cytoplasmic male sterility and its restoration. Plant Cell Rep. 2007, 26, 1627-1634. [CrossRef]

12. Majeed, S.; Malik, T.A.; Rana, I.A.; Azhar, M.T. Antioxidant and physiological responses of upland cotton accessions grown under high-temperature regimes. Iran. J. Sci. Technol. Trans. A Sci. 2019, 43, 2759-2768. [CrossRef]

13. Salman, M.; Khan, A.A.; Rana, I.A.; Maqsood, R.H.; Azhar, M.T. Genetic architecture of relative cell injury and some yield related parameters in Gossypium hirsutum L. Turk. J. Field Crop. 2016, 21, 246-253. [CrossRef]

14. Bibi, A.C.; Oosterhuis, D.M.; Gonias, E.D. Photosynthesis, quantum yield of photosystem II and membrane leakage as affected by high temperatures in cotton genotypes. J. Cotton Sci. 2008, 12, 150-159.

15. Karademir, E.; Karademir, C.; Sevilmiş, U.; Başal, H. Correlations between canopy temperature, chlorophyll content and yield in heat tolerant cotton (Gossypium hirsutum L.) genotypes. Fresenius Environ. Bull. 2018, 27, 5230-5237.

16. Pettigrew, W. Environmental effects on cotton fiber carbohydrate concentration and quality. Crop. Sci. 2001, 41, 1108-1113. [CrossRef]

17. Guinn, G. Causes of Square and Boll Shedding in Cotton; US Department of Agriculture, Agricultural Research Service: Washington DC, USA, 1982.

18. Raper, T.; Oosterhuis, D.; Pilon, C.; Burke, J.; Coomer, T. Evaluation of 1-methylcyclopropene to reduce ethylene driven yield reductions in field-grown cotton. In Summaries of Arkansas Cotton Research; Oosterhuis, D.M., Ed.; University of Arkansas System Division of Agriculture: Little Rock, AR, USA, 2013; Volume 91, pp. 91-95.

19. O'Connor, C.M.; Adams, J.U.; Fairman, J. How do cells decode genetic information into functional proteins? In Essentials of Cell Biology; NPG Education: Cambridge, MA, USA, 2010; Volume 1, p. 54.

20. Angers, B.; Castonguay, E.; Massicotte, R. Environmentally induced phenotypes and DNA methylation: How to deal with unpredictable conditions until the next generation and after. Mol. Ecol. 2010, 19, 1283-1295. [CrossRef]

21. Anderson, P.; Agrell, J. Within-plant variation in induced defence in developing leaves of cotton plants. Oecologia 2005, 144, 427-434. [CrossRef]

22. PSC Approves 2 New Bt Cotton Varieties Developed by CCRI Multan with Production Potential of 50 Munds per Acre. Available online: https:/ / www.urdupoint.com/en/pakistan/psc-approves-2-new-bt-cotton-varieties-develo-1154689.html (accessed on 13 October 2021).

23. Central Cotton Research Institute, Multan. Cotton Varieties. Available online: http:/ /www.ccri.gov.pk/varieties.html\# (accessed on 14 October 2021).

24. Rahman, M.U.; Zafa, Y. Registration of 'NIBGE-2' cotton. J. Plant Regist. 2007, 1, 113. [CrossRef]

25. Research Divisions, Achievements, Nuclear Institute for Agriculture and Biology, Faisalabad. Available online: http://www.niab. org.pk/mutation.htm (accessed on 14 October 2021).

26. Nortin, J. Testing of plum pollen viability with tetrazolium salts. Proc. Amer. Soc. Hort. Sci. 1966, 89, 132-134.

27. Sullivan, C.Y. Mechanisms of Heat and Drought Resistance in Grain Sorghum and Methods of Measurement. In Sorghum in Seventies; Oxford \& IBH Pub. Co.: New Delhi, India, 1972.

28. Steel, R.G.; Torrie, J.H.; Dickey, D.A. Principles and Procedures of Statistics, a Biometrical Approach; McGraw-Hill: New York, NY, USA, 1997.

29. Statistix 8.1. User's Manual. Analytical Software, Tallahassee. 2003. Available online: https://statistix.informer.com/8.1/ (accessed on 28 February 2020).

30. Haynes, W. Tukey's test. In Encyclopedia of Systems Biology; Dubitzky, W., Wolkenhauer, O., Cho, K.H., Yokota, H., Eds.; Springer: New York, NY, USA, 2013; pp. 2303-2304.

31. Song, G.; Jiang, C.; Ge, X.; Chen, Q.; Tang, C. Pollen thermotolerance of upland cotton related to anther structure and HSP expression. Agron. J. 2015, 107, 1269-1279. [CrossRef]

32. Hu, W.; Liu, Y.; Loka, D.A.; Zahoor, R.; Wang, S.; Zhou, Z. Drought limits pollen tube growth rate by altering carbohydrate metabolism in cotton (Gossypium hirsutum) pistils. Plant. Sci. 2019, 286, 108-117. [CrossRef]

33. Wang, J.; Sun, N.; Deng, T.; Zhang, L.; Zuo, K. Genome-wide cloning, identification, classification and functional analysis of cotton heat shock transcription factors in cotton (Gossypium hirsutum). BMC Genom. 2014, 15, 1-19. [CrossRef] [PubMed]

34. Rahman, H.; Malik, S.A.; Saleem, M. Heat tolerance of upland cotton during the fruiting stage evaluated using cellular membrane thermostability. Field Crops Res. 2004, 85, 149-158. [CrossRef]

35. Hadacek, F. Secondary metabolites as plant traits: Current assessment and future perspectives. Crit. Rev. Plant Sci. 2002, 21, 273-322. [CrossRef]

36. Goodwin, S.M.; Jenks, M.A. Plant cuticle function as a barrier to water loss. Plan. Abiotic Stress 2005, 21, 14-36.

37. Grigorova, B.; Vaseva, I.; Demirevska, K.; Feller, U. Combined drought and heat stress in wheat: Changes in some heat shock proteins. Biol. Plant 2011, 55, 105-111. [CrossRef]

38. Melgar, J.C.; Guidi, L.; Remorini, D.; Agati, G.; Degl'innocenti, E.; Castelli, S.; Baratto, M.C.; Faraloni, C.; Tattini, M. Antioxidant defences and oxidative damage in salt-treated olive plants under contrasting sunlight irradiance. Tree Physiol. 2009, 29, 1187-1198. [CrossRef]

39. Petrović, S.; Zvezdanović, J.; Marković, D. Chlorophyll degradation in aqueous mediums induced by light and UV-B irradiation: An UHPLC-ESI-MS study. Radiat. Phys. Chem. 2017, 141, 8-16. [CrossRef] 
40. Bassman, J.H. Ecosystem consequences of enhanced solar ultraviolet radiation: Secondary plant metabolites as mediators of multiple trophic interactions in terrestrial plant communities. Photochem. Photobiol. 2004, 79, 382-398. [CrossRef]

41. Salama, H.M.; Al Watban, A.A.; Al-Fughom, A.T. Effect of ultraviolet radiation on chlorophyll, carotenoid, protein and proline contents of some annual desert plants. Saudi J. Biol. Sci. 2011, 18, 79-86. [CrossRef]

42. Cottee, N.S.; Tan, D.K.Y.; Bange, M.P.; Cothren, J.T.; Campbell, L.C. Multi-level determination of heat tolerance in cotton (Gossypium hirsutum L.) under field conditions. Crop. Sci. 2010, 50, 2553-2564. [CrossRef]

43. Jamil, A.; Khan, S.J.; Ullah, K. Genetic diversity for cell membrane thermostability, yield and quality attributes in cotton (Gossypium hirsutum L.). Genet. Resour. Crop. Evol. 2020, 67, 1405-1414. [CrossRef]

44. Yang, G.; Rhodes, D.; Joly, R.J. Effects of high temperature on membrane stability and chlorophyll fluorescence in glycinebetainedeficient and glycinebetaine-containing maize lines. Funct. Plant Biol. 1996, 23, 437-443. [CrossRef]

45. Ristic, Z.; Bukovnik, U.; Prasad, P.V. Correlation between heat stability of thylakoid membranes and loss of chlorophyll in winter wheat under heat stress. Crop. Sci. 2007, 47, 2067-2073. [CrossRef]

46. Gosavi, G.; Jadhav, A.; Kale, A.; Gadakh, S.; Pawar, B.; Chimote, V. Effect of heat stress on proline, chlorophyll content, heat shock proteins and antioxidant enzyme activity in sorghum (Sorghum bicolor) at seedlings stage. Indian J. Biotechnol. 2014, 13, 356-363.

47. Dolatabadian, A.; Sanavi, A.M.; Harifi, M.S. Effect of ascorbic acid (Vitamin C) leaf feeding on antioxidant enzymes activity, proline accumulation and lipid peroxidation of canola (Brassica napus L.) under salt stress condition. J. Sci. Tech. Agri. Nat. Res. 2009, 13, 611-620.

48. Kamal, M.A.; Saleem, M.F.; Wahid, M.A.; Shakeel, A. Effects of ascorbic acid on membrane stability and yield of heat stressed Bt cotton. J. Anim. Plant. Sci. 2017, 27, 192-199.

49. Zhang, Z.; Shang, H.; Shi, Y.; Huang, L.; Li, J.; Ge, Q.; Gong, J.; Liu, A.; Chen, T.; Wang, D. Construction of a high-density genetic map by specific locus amplified fragment sequencing (SLAF-seq) and its application to Quantitative Trait Loci (QTL) analysis for boll weight in upland cotton (Gossypium hirsutum.). BMC Plant Biol. 2016, 16, 1-18. [CrossRef]

50. Campbell, B.; Chee, P.; Lubbers, E.; Bowman, D.; Meredith, W., Jr.; Johnson, J.; Fraser, D.; Bridges, W.; Jones, D. Dissecting genotype $\times$ environment interactions and trait correlations present in the Pee Dee cotton germplasm collection following seventy years of plant breeding. Crop. Sci. 2012, 52, 690-699. [CrossRef]

51. Mubarik, M.S.; Ma, C.; Majeed, S.; Du, X.; Azhar, M.T. Revamping of cotton breeding programs for efficient use of genetic resources under changing climate. Agronomy 2020, 10, 1190. [CrossRef]

52. Reddy, K.; Hodges, H.; Reddy, V. Temperature effects on cotton fruit retention. Agron. J. 1992, 84, 26-30. [CrossRef]

53. Liu, Z.; Yuan, Y.L.; Liu, S.Q.; Yu, X.N.; Rao, L.Q. Screening for high-temperature tolerant cotton cultivars by testing in vitro pollen germination, pollen tube growth and boll retention. J. Integr. Plant Biol. 2006, 48, 706-714. [CrossRef]

54. Khan, A.I.; Khan, I.A.; Awan, F.S.; Sadaqat, H.A.; Bahadur, S. Estimation of genetic distance based on RAPDs between 11 cotton accessions varying in heat tolerance. Genet. Mol. Res. 2011, 10, 96-101. [CrossRef] [PubMed] 